\title{
Elite y pueblo en la independencia en el Perú: Estudios recientes de historia política, social y económica'
}

\author{
Daniel MORÁN
}

John Fisher. El Perú borbónico, 1750-1824. Lima: IEP, 2000, 360p.

Gustavo Montoya. La independencia del Perú y el fantasma de la revolución. Lima: IEP-IFEA, 2002, 198p.

Heraclio Bonilla. Metáfora y realidad de la independencia en el Perú. Lima: Fondo Editorial del Pedagógico San Marcos, 2007, 190p.

Elizabeth del Socorro Hernández García. La elite piurana y la independencia del Perú: La lucha por la continuidad en la naciente república (17501824). Lima: IRA-PUCP-Universidad de Piura, 2008, 476p.

El estudio de los procesos de independencia en América Latina viene suscitando una cantidad incontenible de publicaciones y debates académicos atrayentes a puertas de las celebraciones de los bicentenarios. Así, un recorrido fugaz pero inteligente por la historiografía latinoamericana de estos últimos años nos permite observar las diversas tendencias y las múltiples temáticas que esta historiografía viene abordando desde el campo de la renovada historia política y cultural (tomando como paradigma las investigaciones

\footnotetext{
' Estas reflexiones fueron desarrolladas y presentadas en el Seminario Problemas de Historia Económica en América Latina a cargo del Dr. Juan Manuel Palacio en la Maestría en Historia del IDAES (abril-julio, 2009), a él un sincero agradecimiento por sus aportaciones y críticas constructivas al texto. Igualmente, a María Isabel Aguirre y Frank Huamaní, amigos de ruta y amantes de la historia. Por otro lado, en este recuento historiográfico se analizan solamente libros de autores publicados entre el 2000 y el 2008 referidos al proceso de independencia del Perú que mantienen una estrecha relación con la historia política, social y económica. Por lo tanto, quedan descartados artículos, compilaciones y traducciones de libros que no se ajusten al ejercicio académico sugerido en este trabajo. Sin embargo, es útil señalar como referencia general estas investigaciones: Scarlett O' Phelan Godoy (compiladora): La independencia en el Perú. De los borbones a Bolívar. Lima: PUCPIRA, 2001; Víctor Peralta Ruiz. En defensa de la autoridad. Política y cultura bajo el gobierno del virrey Abascal. Perú, 1806-1816. Madrid: CSIC-Instituto de Historia, 2002; y Alejandro Rey de Castro. El pensamiento político y la formación de la nacionalidad peruana, 1780-1820. Lima: Fondo Editorial de CCSS-UNMSM, 2008.
} 
de Francois-Xavier Guerra), la historia social íntimamente relacionada al estudio de las clases populares como agentes de participación política, hasta los sugerentes análisis de los proyectos políticos que los grupos de poder buscaron establecer a través de las armas y la lucha ideológica.

En esas perspectivas, la historiografía peruana reciente de la independencia ha mostrado estas mismas inquietudes marcando, sin embargo, algunas variantes en el análisis mismo del proceso. La historia política y cultural ha desarrollado mayormente el campo de la crisis de autoridad y las alternativas políticas (aunque complejas y contradictorias) que los grupos de poder y los mismos sectores populares adoptaron a consecuencia de los funestos acontecimientos abiertos en España con la invasión francesa de 1808. Por ejemplo, el estudio de la prensa, las redes de comunicación, los espacios de sociabilidad, la opinión pública, las elecciones, la cultura política, la educación, el teatro, etc. Por su parte, la historia social (para nada desligada de lo político) ha incidido en un estudio sistemático de las protestas sociales unidas a los vaivenes de las luchas políticas de las guerras de independencia y los efectos económicos que éstas habrían ocasionado. Está última tendencia, preocupada por los costos y beneficios económicos que produjo la independencia, ha prestado atención a las continuidades y los cambios generados por aquellos sucesos, en una perspectiva de proceso que debiera comprender desde el siglo XVIII borbónico hasta mediados del siglo XIX republicano.

En ese sentido, los cuatro libros analizados en este breve alcance historiográfico de la independencia en el Perú han abierto varios campos de análisis históricos sugerentes. En primer lugar, todos ellos inciden en las consecuencias de la crisis hispana de 1808 para la aceleración de las independencias latinoamericanas, dejando con este argumento rotas las visiones conservadoras de la historia que veían en la independencia la consumación de causales netamente internas. En segundo término, estos trabajos debidamente vinculados permiten calibrar y darle el peso correspondiente a la esfera política, social y económica en la configuración del proceso de ruptura con España. En tercer lugar, estas investigaciones muestran las relaciones peculiares y contradictorias que los grupos de poder y las mismas clases populares asumieron en las coyunturas específicas de la emancipación, además de poner al descubierto los intereses particulares y las divergencias internas de los grupos como consecuencia de la trayectoria recorrida por las sociedades en tiempos de turbulencias sociales. Finalmente, estos textos sugieren un análisis de larga duración, a pesar que uno de ellos se circunscriba a un período corto y que abarque un área territorial más amplia, para comprender así las variantes, relaciones y las semejanzas entre los diversos espacios regionales en donde los distintos grupos sociales convergen, disputan el poder y van creando una 
nueva configuración política que terminará en la instalación de la república a pesar de la endeble situación social y económica de esos años.

\section{El Perú Borbónico}

John Fisher, historiador económico que estudia el período borbónico y cómo este influye en los movimientos sociales y las estrategias políticas de los grupos de poder, ha desarrollado y criticado duramente en su último libro, de más de treinta años de intensa investigación (todo un experto en estos asuntos), ciertos argumentos desacertados o mitos historiográficos de la historia económica de la independencia. En primer lugar, Fisher señala que puede entenderse a las reformas borbónicas como una compleja de red de cambios administrativos, fiscales, judiciales y militares que buscó como objetivo principal mejorar las defensas imperiales (p. 105). Sin embargo, en la actualidad, en apreciación de Fisher, se está cuestionando la idea de que estas reformas representaron un proceso cohesivo y de cambio racional que habría ocasionado un periodo de prosperidad que "permitió a España explotar nuevos recursos en América." Por el contrario, la historiografía está sustentando que fue "un proceso dubitativo, incierto e incompleto [...] que buscaron explotar antes que iniciar el crecimiento económico" (p. 64). De ahí, el argumento reiterativo de que América continuó siendo para España sobre todo una fuente de metales preciosos.

Esta idea es ejemplificada muy bien por el autor cuando afirma que entre las coyunturas de 1785-1796 y 1797-1820, el virreinato peruano siguió constituido en un mercado favorable para las exportaciones españolas fundamentalmente por la fortaleza de su economía basada en la plata, el manejo firme contra el contrabando y el ingreso a sus puertos de naves neutrales. A partir de esta constatación es como Fisher refuta la tesis de que con la implantación del comercio libre en 1778 se "destruyó la importancia comercial del Callao como destino, y la de Lima como centro distribuidor" (pp. 120-121). Esto no niega que el poder económico limeño disminuyera frente al incremento sustancial de otras regiones como el Río de la Plata. Pero esa disminución no significó quiebra económica ni mucho menos desplazamiento de la supremacía colonial.

Por su parte, el incremento de la producción minera y la recaudación fiscal demuestran otra vez un aumento sostenido de los ingresos económicos en el virreinato peruano (pp. 130-137). Así, los resultados de estos cambios fueron diversos. Por ejemplo, la compleja red de reformas tuvo efectos distintos en la comunidad mercantil, porque mientras para algunos ocasionó su estancamiento y decadencia, para otros permitió una sostenida prosperidad económica. Todo ello dependía de la ubicación socio-económica en que se encontraron y el contexto de transformaciones específicas que 
vivieron (p.126). En conclusión, para Fisher, estas evidencias de la economía colonial permiten afirmar que no es posible seguir creyendo "el mito historiográfico de que el virreinato fue la víctima económica sudamericana del programa borbónico de reforma imperial" (p. 137). Incluso, el comercio libre, la nueva forma de control económica y comercial de la corona sobre sus súbditos americanos, no hacía nada más que reglamentar algo que ya estaba presente en el comercio colonial (pp. 28-29).

Con estas evidencias, el autor sugiere determinados argumentos sobre las consecuencias que las reformas ocasionaron en la conformación social y el comportamiento político de los grupos sociales en el período borbónico. Así, es notoria la tesis de que la reorganización defensiva y militar del virreinato ante posibles ataques extranjeros terminó siendo empleada para mantener el orden interno (cap. 2). Esta constatación refleja la existencia de una doble lectura de las reformas borbónicas porque mientras las modificaciones económicas permitían la acumulación de metales preciosos para la metrópoli, terminaban impulsando también los movimientos sociales en las colonias. Todo esto no hace más que probar el carácter cambiante, complejo e inestructurado de la política española a pesar de sus esfuerzos por la "modernización" de América. Sin embargo, los movimientos sociales incentivados por estos cambios, incluso el de Túpac Amaru en 1780 y el del Cuzco de 1814, no representaron en términos de sus objetivos sociales y económicos serias amenazas revolucionarias al status quo (p. 183). Por el contrario, estas rebeliones, descontentos locales y regionales, adquirieron el significado adverso de lo que deseaban conseguir, es decir, en el imaginario de la época, fueron utilizadas políticamente por las autoridades coloniales para hacer ver la amenaza potencial que toda actividad revolucionaria podía ocasionar a los intereses y a la posición socio-económica privilegiada de los grupos criollos (pp. 195-196). Además, existió algo más rotundo que empujó a los grupos de poder a rechazar todo movimiento insurgente en el Perú: la repugnancia española y criolla por el triunfo de toda corriente separatista que pudiera ofrecer el acceso de los indios al poder económico y político del virreinato (p. 179).

En esas circunstancias, los grupos criollos, que deberían haber estado llamados a organizar las luchas por la independencia, ante el predominio político de los españoles y las excesivas cargas fiscales de la corona, adoptaron el fidelismo como una acción más segura que la propuesta de una férrea lucha revolucionaria (cap. 6). Entonces, estos movimientos fueron nada más que amenazas y no concreción de un movimiento radical, pues era obvio el carácter pragmático de los criollos, que temían un desborde popular que afectara su posición de superioridad (seriamente debilitada por las reformas) en el ordenamiento social (pp. 148, 191). Asimismo, era algo 
incuestionable la fragmentación social de los propios grupos indígenas y la enemistad de estos con los negros, castas y mestizos.

Por ello, un movimiento que aglutinara a todos estos grupos sociales y asumiera un programa de corte revolucionario estuvo más en los sueños e ideales que en realidad concreta (p.167). No obstante, de estas premisas que relacionan los intereses económicos con la preeminencia social y el poder político, se puede insinuar, en ideas de Fisher, una hipótesis ciertamente coherente: que antes de la llegada de San Martín al Perú, los movimientos a favor de la "insurgencia y el protonacionalismo se manifestaron en la sierra india, antes que en la aristocrática Lima" (p. 182). En resumidas cuentas, entre 1809-1815, la participación peruana en el proceso de independencia tuvo carácter regional (Cuzco, Arequipa y Huánuco), en contraposición y desafío al poder y predominio de Lima como centro de la dominación colonial en el Perú.

\section{Metáfora y realidad}

Este argumento sugerente de Fisher ha sido indicado con cierta advertencia y alguna precaución por Heraclio Bonilla. Este último, sesudo investigador y crítico feroz de los mitos historiográficos de la historia tradicional, parte de la premisa que los historiadores, después de estar fascinados durante décadas por el estudio de los grandes hombres en la historia y su participación militar en las mismas, han virado su atención sobre las reflexiones sociales y políticas relacionadas a los intereses económicos que éstos y los grupos populares sostuvieron durante la crisis hispana y el último tramo de la independencia política. Así, en la intención de evaluar y explicar la historia de ese proceso y las diversas tendencias, avances, atrasos y desarrollos de la historiografía, Bonilla ha reunido en este libro un conjunto de sugerentes trabajos que buscan repensar la independencia desde un ángulo que incide en advertir el comportamiento de las clases populares a partir del análisis de las condiciones económicas y los intereses políticos de los grupos de poder en tiempos de turbulencias sociales.

En ese sentido, textos como: Clases populares y Estado en el contexto de la crisis colonial, Bolívar y las guerrillas indígenas en el Perú, La oposición de los campesinos indios a la República: Iquicha, 1827 y el sugerente ensayo Rey o República: el dilema de los indios frente a la independencia, no hacen más que demostrar la constante preocupación del autor por la praxis política y la participación social del pueblo en la independencia. Recordemos que Bonilla, al igual de Fisher, ha venido desarrollando estos temas por más de tres décadas, insistiendo en que las clases populares en su conjunto no apoyaron decisivamente la ruptura con España. Por lo tanto, el hilo conductor de todo el texto está circunscrito, principalmente, 
a evaluar la trayectoria del comportamiento político, social y militar de las clases populares en dicho proceso.

Así, Bonilla, con la utilización de ciertos volúmenes de la propia Colección Documental de la Independencia del Perú, los denominados "ladrillos blancos", intenta probar los débiles argumentos de la historiografía nacionalista en torno a la participación de los sectores populares. Para el autor, el análisis de la rebelión de Túpac Amaru II en 1780, del movimiento social en Huánuco en 1812 y de los disidentes del Cuzco en 1814, muestran la débil coalición social entre las masas indígenas y criollas, pues, los líderes de estos movimientos sociales no habían logrado unir en una sola propuesta los diversos intereses contradictorios de todos estos grupos en el momento de la independencia. Además, se percibe como una terrible dificultad social el claro componente regional y localizado de las revueltas sociales (cap. 3 y 6). En pocas palabras, eran más una lucha por la autonomía regional que por la independencia de España. Al respecto, las investigaciones de Waldemar Espinoza, Scarlett O'Phelan, Alberto Flores Galindo, Christine Hunefeldt, Núria Sala I Vila, Susana Aldana y otros, han argumentado hasta el cansancio esa grave barrera étnica y social que los diversos grupos populares tuvieron que enfrentar en el desenlace de las guerras de independencia.

Por aquella realidad, señala Bonilla, el estudio de las clases populares ha mantenido esa dicotomía y esas dificultades, ¿apoyaron o no la independencia?, ¿fueron patriotas o realistas?, a pesar que con esas interrogantes no se ha podido avanzar seriamente en la comprensión del desarrollo político y social de indios, negros y castas en la guerra separatista (cap. 2 y 4). En apreciación del autor, no era solamente importante presentar una serie de documentos y "probar" esa participación popular, era preciso y necesario trabajar con ideas, indagar sistemáticamente y con nuevas interrogantes esos volúmenes de la Colección Documental, y conseguir nuevas fuentes en los diversos archivos históricos (pp. 75-77). Solamente el descubrimiento, la nueva lectura de los documentos, las nuevas interrogantes planteadas y un sofisticado marco teórico y metodológico, permitirán un análisis más real y satisfactorio de la participación popular en este proceso (p. 151).

Otro argumento importante que subyace en la investigación está referido a la propuesta de indagar sistemáticamente la participación popular, la de los grupos criollos y la férrea lucha militar que las autoridades coloniales, apoyadas por la elite, llevaron a cabo para sofocar estos movimientos, en una perspectiva que priorice el análisis de los espacios regionales en íntima relación con las demás áreas coloniales y los intrincados sucesos de la península (pp. 77-78). En esta temática, Bonilla ha estudiado el complejo pero estimulante caso de los indios de Iquicha (cap. 5). La oposición de 
estos últimos a la República en 1827, fue una experiencia que los llevó a su alianza con los españoles. Sin embargo, los intereses y reivindicaciones de los dos grupos eran diferentes. Los indígenas buscaban la eliminación del viejo tributo colonial (paradójicamente, en 1827), la autonomía de sus autoridades locales, el rechazo a los atropellos del ejército patriota y la firme defensa de la religión católica. Por su parte, los blancos aspiraban el restablecimiento del orden colonial y del imperio de Fernando VII para recuperar sus privilegios perdidos. Aquellos intereses contrapuestos, percibidos también en las rebeliones sociales de fines del periodo colonial, llevarían al fracaso del levantamiento. Tiene que entenderse que la oposición de los iquichanos al nuevo Estado republicano puede ser el resultado perdurable de la herencia colonial, ejemplificada en las fisuras sociales, raciales y económicas que las sociedades indias mantuvieron entre ellas y con los otros grupos sociales (p.149). Este caso se asemeja a los estudios de la participación popular de "colombianos", "bolivianos" y ecuatorianos", que el autor señala, brevemente, como una manera didáctica de explicar que las características de la realidad peruana no eran propias, sino que era compartida en los países andinos (pp. 134, 151-152). Esta constatación ayuda a tener un panorama más global y vinculante de las guerras de independencia en América Latina.

Sin embargo, ¿el comportamiento de estos grupos populares era únicamente por un interés político y social, local o regional? Heraclio Bonilla considera que detrás de esa preeminencia subyacen los intereses económicos que el pueblo y los grupos de poder podían ganar o perder en una coyuntura revolucionaria. Era claro que el triunfo de una revolución popular afectaría terriblemente los privilegios y la supremacía política y económica de la elite (p. 130). Pero era también cierto que dentro de las mismas clases populares los "intereses comerciales" y la "tradicional segmentación étnica" jugaban en contra de una "eficiente fusión interna de la población india" (p. 80). Esas disparidades se volverían a presentar en la participación que cumplieron las guerrillas indígenas desde la declaración simbólica de independencia por San Martín y los triunfos definitivos de las fuerzas de liberación en Junín y Ayacucho en 1824 (pp. 117-120). Se percibe que lejos de desear fervientemente la independencia o rechazarla, los grupos populares asumieron funciones en la guerra de acuerdo a sus intereses o al menos en defensa de su propia existencia como sector social. Además, era obvia la presencia indígena en el conflicto tanto en las filas patriotas como realistas. Esto no hace más que mostrar los complicados comportamientos de estas clases bajas en un contexto en donde su adhesión estuvo supeditada al uso de mecanismos coactivos de reclutamiento, del engaño y la concesión coyuntural de ciertas exenciones (pp. 122-124). Incluso, los líderes de las guerrillas no tuvieron una posición monolítica frente a la independencia, sino que esta se modificó de acuerdo 
a los acontecimientos militares y políticos y al propio temor causado en las instancias de poder, por el ímpetu desenfrenado y peligroso de las fuerzas indias en la guerra. Este argumento explica por qué los sectores indígenas no formaron elementos efectivos de los ejércitos formales, desempeñándose únicamente en funciones específicas de respaldo, acoso, vigilancia o espionaje (pp. 123, 129-131).

Estas evidencias advierten que la tesis del autor de que la independencia criolla no supuso libertad económica, inclusión política ni mucho menos acceso social en igualdad de condiciones de las clases populares, es una realidad totalmente incuestionable. Por ello, Bonilla sugiere que durante la independencia y los inicios de la república deberíamos constatar más continuidades que cambios efectivos (p. 173). Y, en ese punto, la posición económica y la autoridad política eran, precisamente, lo que marcaba la diferencia real entre los grupos de poder y los sectores marginales. Entonces, la trayectoria de los movimientos sociales en la independencia debe entenderse en tres coyunturas específicas en donde los grupos de poder establecieron conexiones, alianzas, conflictos y divergencias tanto económicas, políticas como sociales con los sectores populares (cap. 3, 4 y 6). El análisis sistemático de estas coyunturas, -que van desde las grandes rebeliones anticoloniales del sur andino de 1780-81, pasando por los levantamientos regionales o locales desarrollados en esta misma zona entre 1812-15, y llegando, finalmente, a las revueltas desatadas entre 1821-27, en donde la preeminencia de los intereses criollos era absoluta y la visión de conjunto de las guerras de independencia consiguieron instalar definitivamente a la república como nueva forma de autoridad y legitimidad política-, arrojarían nuevas explicaciones realmente sugerentes del papel y el significado de los grupos sociales en la independencia.

\section{El fantasma de la revolución}

Ciertamente, Gustavo Montoya, en su primer trabajo de envergadura, ha querido reflexionar críticamente esta última coyuntura del proceso de la emancipación. Parte de la constatación de que la historiografía se ha dedicado más al carácter ensayístico e ideologizado de sus estudios que a mostrar una investigación sostenida en un fondo documental consistente (p. 99). En ese sentido, al autor se circunscribe al estudio vinculante de la participación de las clases populares y la clase dirigente peruana desde el régimen protectoral hasta la llegada de Bolívar en 1823. Esa relación en el análisis de la clase dominante y el pueblo permite advertir el trasfondo de intereses y temores que estos grupos tuvieron en el desenlace de sus propios destinos (p. 17).

Desde la perspectiva de la historia política que analiza la cultura política de los grupos sociales involucrados en los acontecimientos históricos, Montoya 
ha señalado la provocativa tesis "de que el sector indígena se encontró con el conflicto" (pp. 32-33). Este argumento puede dar a entender el "carácter pasivo del pueblo", al señalar un encuentro antes que una búsqueda, pero esto no fue, precisamente, el propósito del autor. Por el contrario, esta idea le permite sugerir que las clases populares si bien fueron empujadas a las guerras de independencia, esa misma presión e inclusión pudo ofrecerles beneficios y una inesperada participación política que, a la vez que lograba la supervivencia como grupo social, podía servir a los intereses de los patriotas para develar todo foco de reacción realista en Lima.

En esa tendencia de análisis Gustavo Montoya ha estudiado detenidamente la participación activa que tuvieron los "cuerpos cívicos", -integrados por pequeños propietarios, comerciantes, menestrales, castas, pardos y esclavos-, en los acontecimientos sucedidos en el gobierno protectoral (cap. 3). Controlar el orden público y contrarrestar la oposición civil realista que amenazaba el régimen de San Martín resultaron los objetivos primordiales de los cuerpos cívicos. Estos fueron creados por Monteagudo y controlados por el ejército libertador para evitar cualquier intento de contrarrevolución de los realistas o un funesto movimiento de revolución social de estos mismos cívicos al verse con el poder de las armas (p. 126). Así, los cuerpos cívicos fueron la expresión política más acabada de las clases populares en la independencia. Monteagudo creó a estas milicias urbanas incentivando un estado de ánimo revolucionario, extinguiendo a los godos enemigos de la libertad y tomando hacia las fuerzas patriotas y el gobierno todas las lealtades posibles y destruyendo todo signo de insubordinación (pp. 118-122). Al ser destituido Monteagudo y haber decretado San Martín la instalación del Congreso Constituyente en 1822, se produjo la fragmentación y redistribución de los cívicos entre las fuerzas patriotas (p. 127). Con este estudio Montoya quiere demostrar que hubo segmentos populares en Lima, como los negros, que fueron politizados y pudieron en las medidas de sus posibilidades obtener ciertos privilegios al negociar su participación política en las guerras de independencia (p. 145).

Como es obvio estas ideas están íntimamente relacionadas a los intereses económicos del protectorado para sobrellevar los costos del conflicto y dejar en una ubicación degradante y sin poder efectivo a los españoles pudientes de Lima. Estas intenciones de los patriotas y las respuestas que dieron los grupos de poder coloniales pueden ayudarnos a entender la otra parte de la historia de la independencia. Así, la defensa del virreinato no llevó implícita solamente un comportamiento político, además formó parte de la pérdida del poder económico de la aristocracia. Por ello, Montoya busca presentar los conflictos políticos y la mutua oposición entre los diversos grupos sociales de la clase dominante colonial ante el arribo de San Martín, sus estrategias y fórmulas políticas pro-realistas que, al final, 
se inclinaron a una transición pacífica con el nuevo gobierno evitando perder sus bienes, posición y prerrogativas en forma irreversible (cap. 2).

Este argumento de transición pacífica se hace explícito cuando el virrey, después de abandonar Lima en 1821, para dirigirse a la sierra y poner allí su asentamiento de la contrarrevolución, la propia autoridad municipal encargada de la capital solicita el ingreso de San Martín y el ejército libertador sin ninguna lucha armada, con la intención de impedir que una revuelta social de la plebe acabara por despojar de todas sus riquezas y privilegios a la clase propietaria de Lima (pp. 101-102). Si bien este hecho demuestra la intención de San Martín por establecer la independencia a partir de las propias iniciativas de los peruanos, las acciones y prácticas que sucedieron después con la política antiespañola de su ministro Monteagudo fueron totalmente diferentes. "Inflamar el odio contra los españoles" fue el principal propósito de Monteagudo, su política de secuestros de bienes y la expulsión de los españoles del Perú le sirvieron para ser calificado como "el jacobino de América" (pp. 113, 129). En estos propósitos fueron importantes las milicias urbanas creadas precisamente por el ministro para controlar a los españoles realistas enemigos de la revolución (pp. 137-145).

Este manejo político del protectorado se vio favorecido por las complicadas relaciones que mantuvieron las clases políticas peruanas en esa coyuntura de la independencia. En apreciación de Montoya en la defensa de Lima concurrieron la mayor parte de los miembros de la clase dominante, pero esa participación estuvo mediatizada, principalmente, por proteger sus intereses de grupo, porque sabían muy bien que dependía de sus decisiones el desenlace del conflicto. Así, utilizaron muchas maniobras y estrategias políticas que terminaron en fracasos porque era casi imposible uniformar intereses contrapuestos y seguir enmascarando la dominación social que habían mantenido sobre la plebe urbana, los siervos indígenas y los esclavos (pp. 73-74). En esas circunstancias se produce la ruptura y desintegración de la clase dominante. Por un lado, estuvieron los miembros del Estado virreinal y el ejército realista, por el otro, los intereses de la aristocracia terrateniente limeña agrupada en la municipalidad de Lima y los grandes comerciantes vinculados al tráfico ultramarino organizados en el Tribunal del Consulado. Y, finalmente, un grupo intermedio que defendía los intereses del Estado colonial español y sus beneficiarios de América (pp. 82, 96).

Con estas evidencias era incuestionable seguir afirmando que frente a la independencia, los grupos dominantes de Lima habrían cerrado filas para sostener la defensa del virreinato (pp. 82-83). En ese sentido, Montoya ha demostrado las diversas tendencias e intereses políticos y económicos divergentes y heterogéneos de estos grupos. Incluso, el autor sugiere la existencia de una real voluntad política de un sector significativo de 
la aristocracia terrateniente a favor de la independencia y del proyecto constitucional propuesto por San Martín, pero que nunca logró prosperar, precisamente, por esas enormes e irreconciliables fisuras e intereses que presentaron los grupos de poder en la etapa final de las luchas de independencia (pp. 81-83). Porque no era solamente un proyecto imaginado la solución a los problemas, se necesitaba del poder de las armas y una base material económica e ideológica lo suficientemente fuerte y cohesionada como para producir un movimiento social de tipo revolucionario que beneficiara a la mayor parte de la sociedad. Definitivamente, lo que sí advierte claramente Montoya es que las elites coloniales fueron las grandes derrotadas del proceso de emancipación (pp. 58-62).

\section{Entre la continuidad y el cambio}

Esta última idea de Gustavo Montoya debe reevaluarse a la luz de nuevas indagaciones que incidan en la participación política, social y económica de los grupos sociales en los espacios regionales. En ese sentido, la propuesta argumentativa y sólidamente documentada de Elizabeth Hernández García, sobre la participación de la elite piurana en el proceso de independencia, no admite duda de la riqueza de estas investigaciones regionales relacionadas al espacio virreinal peruano. Hernández parte de la tesis de que la historiografía de la independencia ha soslayado el análisis de las historias regionales y la vinculación que en estos espacios mantuvieron los grupos sociales ante los vaivenes políticos que significó los movimientos insurgentes en el Perú ( $p$. 18). Así, señala que únicamente los estudios que relacionen a los grupos sociales, que permitan conocer sus identidades y que abarquen incluso la exploración de los intereses comunes o contradictorios que estos poseen permitirá una comprensión más real de su participación y el comportamiento que asumieron en la independencia (p. 42).

En esa perspectiva, la autora examina la trayectoria de la elite piurana en ese proceso, sin dejar de mencionar la presencia de las clases populares. Los grupos prominentes de Piura basaron su poder en la zona estratégica de su territorio, el progreso económico local, las conexiones con otras regiones coloniales propicias para el comercio, la posesión de haciendas, el gobierno político de la región y su identificación como "vecinos nobles de la ciudad" en abierta diferenciación con el pueblo incivilizado y salvaje (cap. 1). Precisamente, esta distinción significó el carácter medular de la superioridad de la elite y, al mismo tiempo, el recelo y el temor constante que sentían por indios y negros como posibles focos potenciales de movimientos revolucionarios. Esto llevó a que los grupos de poder buscaran el control y la subordinación de la plebe y prodigaran asimismo su íntima fidelidad a la corona española (pp. 43-45). 
Como afirmamos, la elite piurana mostró su poder económico a través de la adquisición de haciendas y la participación activa en el comercio, situación que conllevó a posicionarse del gobierno político de la región. Sin embargo, esta misma elite comprendió que eso no era suficiente para destacar e influir en las esferas políticas del poder colonial en América. Por ello, precisaron la educación superior de sus hijos en las principales instituciones educativas de Lima y de otras ciudades con el objetivo de acceder a puestos políticos superiores en la capital del virreinato (cap. 4).

A lo largo del período colonial la elite de Piura evidenció diversos mecanismos de supervivencia que le permitieron mantenerse en la posición de privilegio en que se encontraba (cap. 3). Esos elementos, -como la división social y económica de superioridad de los nobles sobre la plebe, la movilidad social principalmente por factores económicos, el título de nobleza a pesar de ser considerados una "nobleza no titulada", la ascendencia española y la limpieza de sangre, las relaciones de parentesco a través de matrimonios concertados exclusivamente con españoles, la formación superior de sus descendientes y la adjudicación de cargos burocráticos-, supusieron la reafirmación de su poder regional y la fuerte decisión, hasta el último momento de la proclamación de la independencia en Piura, de su tendencia política en clara defensa de sus intereses particulares como grupo social antes que un fervor patriota o un fidelismo declarado (pp. 109-131).

Este comportamiento de la elite piurana puede apreciarse en dos coyunturas específicas de la independencia. Durante la experiencia de la crisis hispana y las Cortes de Cádiz, la elite de Piura logró adquirir un protagonismo político sobresaliente asignándose el control absoluto del Cabildo como el medio y espacio de perpetuación del poder regional (p. 185). Es sintomático que esta institución estuviera en poder de pocas familias, esto permitió que en medio de la crisis peninsular el grupo prominente de Piura se convirtiera en el baluarte del gobierno monárquico y profesará la adhesión a la causa de Fernando VII y el mantenimiento del status quo (pp. 193-197). Los notables estuvieron en una posición política dinámica y dominaron las elecciones para diputados a Cortes, los ayuntamientos y los cabildos constitucionales, estableciendo la continuidad de su poder tradicional en medio de la "política moderna." Así, en la composición del Cabildo "eran otros nombres pero los mismos apellidos" (pp. 226-233). No obstante, esto no significó que la elite fuera un grupo homogéneo sin discrepancias e intereses políticos y económicos. En esa coyuntura se produce el conflicto de dos facciones por el poder: unos, defendiendo los intereses de la elite tradicional y, los otros, recién llegados y buscando posicionarse de un espacio de participación política efectiva. Estos últimos incluso se atrevieron a utilizar a la plebe como un mecanismo disuasivo para que la otra parte aceptara ceder una proporción de su poder ( $p p$. 249-250). A pesar de estos conflictos la elite de Piura mantuvo su lealtad a 
la corona siempre y cuando esto supusiera la seguridad de sus bienes y el reconocimiento de su poder regional (pp. 260-268).

Estas conductas autónomas plagadas de intereses políticos calculados de acuerdo a los cambios coyunturales se verán con mayor claridad en el periodo del desenlace de la independencia. La elite de Piura, ante la amenaza de una revolución social de la plebe, el asedio de Lord Cochrane sobre el estratégico puerto de Paita y el inminente avance de los patriotas, siguió apostando a la seguridad de sus intereses primordiales vinculados al poder español (pp. 271-286). En ese sentido, la proclamación de la independencia en Piura en enero de 1821 debe entenderse como una adhesión coyuntural e interesada de la elite, que se vio presionada por la fuerza militar y política de Torre Tagle, que ya había establecido la independencia en Trujillo (p.303). Incluso, durante los años de la consolidación de la independencia (1821-1824), la elite piurana volvió a demostrar la preponderancia de sus intereses regionales antes que la defensa del nuevo orden. Así, la lucha por el ideal libertario fue una necesidad de subsistencia y el mantenimiento del espacio de poder que esta elite poseía (pp. 352-353). Entonces, esta tesis de la férrea defensa del poder regional y autónomo arrogada por la elite piurana en todo el proceso de la independencia, apostando por la continuidad, se ejemplificó estupendamente bien en la trayectoria política, social y económica de Francisco Javier Fernández de Paredes y Noriega, el último marqués de Salinas (pp. 355-375).

Por lo tanto, Elizabeth Hernández García, a través de este estudio de la elite piurana, ha demostrado en muchos sentidos la existencia de esa conflictividad de intereses autónomos dentro de los grupos de poder regionales que no deben ser soslayados al momento de indagar el papel de estos grupos, relacionados también a los sectores populares, en la configuración del proceso de la independencia peruana.

\section{Atando nudos e interpretando una historia integral de la independencia}

De estos cuatro estudios queda claro que la historiografía peruana de la independencia se ha preocupado por el análisis vinculante de la participación política de los grupos de poder y los sectores populares. Además, de la importancia de la esfera económica en los comportamientos e intereses de los grupos sociales. Igualmente, se ha sugerido investigaciones que relacionen el centro de poder colonial con sus espacios regionales. Porque únicamente a través de esa nueva lectura se podría hablar de una historia integral del proceso de la independencia en el Perú. Incluso, estos argumentos necesitarían precisar coyunturas de análisis, áreas de estudio y la incidencia global de la historia de las guerras de independencia para entender una actuación política determinada. 
En ese sentido, señalar que la participación peruana en la independencia hasta 1814 fue regional no debe sorprendernos, sino advertirnos del gran poder de esos espacios en la estructura del sistema colonial. Asimismo, de las distintas percepciones e intereses de estos "grupos periféricos" con respecto a la preeminencia de la elite limeña. La actuación de las mismas clases populares debe verse como un mecanismo de supervivencia y defensa de los intereses propios de su grupo social en un proceso incierto en donde ni la misma elite, detentadora del poder, asumía una conducta política totalmente declarada salvo la continuidad de su preeminencia e intereses particulares. Entonces, las investigaciones de la composición social relacionadas a la esfera política y la situación económica de los grupos sociales a nivel regional, nacional y dentro del proceso de las revoluciones hispánicas deben ser, en estos momentos de las celebraciones de los bicentenarios, una preocupación primordial de la historiografía en su conjunto. Solamente la comprensión de estas realidades como parte de un todo orgánico y diverso a la vez, podría ayudarnos a entendernos a nosotros mismos, a nuestras sociedades latinoamericanas y las connotaciones que estas efemérides nacionales han adquirido hasta la actualidad. No se trata de exorcizar el pasado buscando culpables y focos de críticas inhumanas, sino de comprenderlo en su tiempo y vicisitudes, para sugerir salidas que permitan atar nudos sueltos e intereses contrapuestos afirmando una historia integral en donde todos los peruanos estemos presente sin signos de exclusión ni aires de superioridad de unos contra otros. Pero esto es, como la independencia, todo un proceso que se espera construir a pesar de las dificultades en el camino. A todo ello deberían apuntar los estudios históricos que se emprendan en adelante, no por simple motivación académica sino por una necesidad social inevitable. 